\title{
Sources, Extents and Factors for the Proliferation of Urban Noise Pollution in Wolaita Sodo city, Wolaita zone, Ethiopia
}

\author{
Melese Mesene $^{1}$, Tamirat Mengistu ${ }^{2}$ \\ ${ }^{1}$ Department Of Sociology, College Of Social Sciences \& Humanities, Madda Walabu University, Bale Robe, Ethiopia, P.O Box 247 \\ ${ }^{2}$ Department Of Sociology, College Of Social Science, Wolaita Sodo University, Wolaita Sodo, Ethiopia, P. O. Box: - 138 \\ DOI: 10.29322/IJSRP.11.07.2021.p11534 \\ http://dx.doi.org/10.29322/IJSRP.11.07.2021.p11534
}

\begin{abstract}
Noise pollution is an unwanted, unpleasant or disagreeable sound that causes discomfort to all living beings. Urban noise pollution is one of the problems of people who live in an urban area which causes different health complications and social problems. The major aim of this study was to explore the sources, extent and factors for proliferation of noise pollution in the study area. To attain the sought objectives of the study, mixed methods approach of research was employed. Key informant interviews, in-depth interviews, Focus Group Discussion, Survey and Documentary analysis were methods of data collection in the study. The findings of the study indicate that; traffic congestion and vehicles, loud speakers of religious institutions, announcements by loud speakers, night clubs, social events, building and construction works, wood and metal work machines, garage and welding works are major sources of noise pollution. The problem of noise pollution is aggravated by such factors as rapid urbanization, rapid population growth, road network and rapid increase of vehicles, the competition of religious institutions, and technological advancement. The extent each source emitting noise to the environment is above the standard given by EPA, which is adopted from WHO guidelines.
\end{abstract}

Index Terms- Noise Pollution, Proliferation, Sources, Extent, Factors

\section{INTRODUCTION}

$\mathrm{U}$ rban noise pollution is one of the problems of people who live in urban area and it is a cause for different health complications and social problems. Scholarly defined noise pollution is an unwanted, unpleasant or disagreeable sound that causes discomfort to all living beings. Similarly, Goines \& Hagler (2007) defined noise pollution as the form of air pollution that is audible unwanted sound that poses a threat to a person's health and wellbeing. Literature indicates that; noise is conveniently and concisely unwanted sound that creates annoyance and interferes in conversation, disturbs sleep and teaching-learning process, reduce work efficiency, causing stress and challenge to public health and it is the silent killer problem growing day-by-day (WHO, 2018; Gour, 2013). Besides WHO has seen community noise as noise emitted from all sources, depending up on the position researchers holds, noise has been seen from different perspectives and even sometimes it lacks real measurement to exactly define it. By sharing the definitions given by different scholars; this study sees noise as; a sound that is unwanted to humans, but human has the right to judge either the sound can be called noise or not as a recipient (Kiely, 1997).

At present, noise pollution is considered as one of the key problems of urban communities that has numerous hazardous effects on the urban environment and may result in a great deal of costs on the society. Exposure to noise pollution brings changes in mood of person and it may be varied based on mood of people. People who exposed to noise are less happy and more depressed. In combination with provocation or pre-existing anger or hostility, exposure to noise may trigger aggression. There is a concern to high level continuous noise exposure to contribute to the susceptibility of school children to feelings of helplessness (WHO, 1999, \& 2001).

Urban areas are generally noisier than rural areas, because larger numbers of people live in urban areas and different activities performed in urban areas. Urban noise levels are a complex mixture of noises from transportation, factories, industries, machines, people etc (Morgan, 2015). Gangwar (2006) also described that the increasing number of vehicles, musical instruments, small scale industries, and human activities in urban areas are the main sources of noise pollution. In addition to an ever-increasing number of vehicles on roads, the sound caused by the cars and exhaust system of autos, trucks, buses and motorcycles is the chief reason for noise pollution in urban areas.

In residential areas, noise may also stem from mechanical devices used for home consumptions as; heat pumps, ventilation systems and traffic, as well as voices, music and other kinds of sounds generated by neighbours as lawn 
movers, vacuum cleaners and other household equipment, music reproduction and noisy parties. Aberrant social behaviour is a well-recognized noise problem in multifamily dwellings, as well as at sites for entertainment. Due to predominantly low-frequency components, noise from ventilation systems in residential buildings may also cause considerable concern even at low and moderate sound pressure levels. According to WHO typical neighbourhood noise comes from premises and installations related to the catering trade (restaurant, cafeterias, discotheques, etc.); from living or recorded music; from sporting events including motorsports; from playgrounds and car parks; and from domestic animals such as barking dogs (WHO, 1999, 2001, \& 2018).

Factors behind the proliferation of noise pollution include; rapid urbanization, industrialization, urban population growth, expansion of road network in urban centres, increase in several motor vehicles, a competition of religious institutions and technological advancement. These are factors for the proliferation of the problem of noise pollution, but are not sources in that they contribute highly to others to produce higher noises and to disturb the environment. They are processes where sources of noise stand on and they are interlinked to each other and to the sources of noise pollution. In some cases, it is difficult to mark clear distinction between factors of noise pollution and sources of noise pollution (Morgan, 2015).

Actions to control noise effects have been an immediate concern for communities in countries of the developed world, as evidenced by a large number of anti-noise laws, regulations and noise policies. However, such actions remain limited in the developing countries, especially in Africa. Ethiopia is among the developing countries whose urban environment has undergone significant changes due to industrialization, rapid urbanization, urban population growth, the expansion of the road network and the increase in the number of motor vehicles and competitions of some of the religious institutions loudspeakers overly disturb the lives of the society. These changes have probably led to an increase in noise levels that have negative effects on citizens (Dana, 2017).

Despite the fact that Ethiopia had developed rules and regulations to control environmental pollution in order to cope with the existing situation, still noise pollution issues continued without end solutions. Urbanization and associated growth in mobility and industrialization have resulted in the intensification of noise in densely populated areas causing an increase in noise exposure. As the population increases in an urban area, industrial activities also increase to meet people's needs, which in turn result in increased noise levels (Assefa, 2014; Berhanu, 2011; Kinfe et al, 2018; Kucha, 2014; Mintesnot, 2018).

Therefore, this study is intended to address issues related to sources of urban noise pollution, extent from each source and factors for the proliferation of noise pollution in Wolaita Sodo city. The sources of noise pollution in the city as traffic congestion and heavy vehicles, loud speakers by religious organizations and announcements by loud speakers, noises from recreational centres, noises from industries and heavy machines and other sources of noise pollution are assessed in the study. The level of noise emitted from each source was measured and factors for the proliferation of urban noise pollution are discussed in detail.

\section{METHODS AND MATERIALS}

\subsection{Study Setting}

Wolaita Sodo city is the administrative capital of Wolaita zone and serves as administrative, commercial and transport centre of Zone. The city is located at $329 \mathrm{~km}$ distance from Addis Ababa via Hosanna and $390 \mathrm{~km}$ via Shashemene. The absolute geographical location of the city is between $06^{\circ} 46^{\prime}-06^{\circ} 59^{\prime}$ North latitude and $36^{0}$ and between $37^{\circ} 42^{\prime}-37^{\circ} 48^{\prime}$ East longitudes and the air condition of the city is in average $20^{\circ} \mathrm{c}$. The total area of the city is 9,100 hectare and according to $4^{\text {th }}$ structural design of the city, the city is structured into seven (07) kebeles, 19 districts, 59 sub-districts and 379 stations and the total population of the city is estimated to 254,295 . The road coverage of the city is $55.5 \mathrm{~km}$ asphalt and $82 \mathrm{~km}$ cobblestone and there are seven main routes in the city which serves as gates for surrounding locations. Regarding the socio-economic profile of the city, there are two hospitals, three health centres and above 54 clinics in the city. There are also above 87 primary and secondary public and private schools, one public university, 2 TVETS and above 5 private colleges in the city. Regarding the transport system, there are above 3,100 vehicles in the city. There are 120 religious' institutions in the City (10 Orthodox, 2 Catholic, 50 Evangelical, 30 Kale Hiwot, 1 Mekaneyesus, 1 Adventist, and 25 others and 4 Mosques \& etc) and there are several small scale enterprises and industries and hotels, restaurants, bars, night clubs and Music shops.

This research is focused on Wolaita Sodo city where the above factors are determined. As it is discussed above there are seven kebeles in wolaita Sodo city and the researcher purposely classified in to two groups that are core kebeles and periphery kebeles. Core kebeles are the kebeles that are found in the central part of the city geographically which include Markato Yushuwa kebele, Mehal kebele, Wadu Amba kebele and Fana womba kebele and the rest three are categorized as periphery. The researcher purposively selected to focus on core kebeles because of high population 
ISSN 2250-3153

density, high rate of urbanization, a presence of many business centres, location of many social institutions, high rate of road network, and other related factors in the core kebeles.

\subsection{Research Design}

According to Creswell (2009), mixed methods research is an approach to inquiry that combines both qualitative and quantitative forms, which involves philosophical assumptions, the use of qualitative and quantitative approaches, and the mixing of both approaches in a study. Mixed method is a method used to broaden understandings by incorporating both qualitative and quantitative research or to use one approach to better understanding, to explain and build on the results from the other approach. To attain the objective of the study mixed approaches of research was employed to this study. The major focus of this study is a qualitative approach, while the quantitative approach is applied to fill the gaps in a qualitative approach. Quantitative data gained from Survey and by measurement through sound level meter are summarized by quantitative analysis method. The qualitative approach is also used to investigate how noise pollutions are originated by human interactions and activities in urban settings by assessing situations on the ground.

\subsection{Methods of Data Collection}

Both quantitative and qualitative data were collected in this study by using different data collection methods.

\subsubsection{Quantitative Data Collection Methods Survey Design}

A survey is a method used to gather information from a sample of a population (Earl 1994). To collect data in a cost-effective and time-saving way, the researcher chooses a cross-sectional survey design to collect data on one point time from the study area. Questionnaires prepared by both open-ended and close-ended questions were distributed to respondents. The questionnaire was self-administered questions which were filled by the respondents themselves. The survey also took place by measuring the level of noise in the selected catchment areas of the city by sound level measurement instrument (SLM). From seven kebeles of Sodo City, the study focused on four core kebeles found in the centre of the city. 201 households were selected from these kebeles by random sampling to answer the questionnaire, 15 religious' institutions, 9-night clubs, 12 wood \& metalwork machines, 4 Garages \& Welding, 3 different type vehicles, 5 busy roads, 8 announcements, 4 small industries (factories), and 8 music shops were selected through purposive sampling to observations and measurement through the sound meter.

\subsubsection{Qualitative data collection Methods}

In-depth interviews, key informant interviews, Focus Group Discussions (FGDs) and observations were employed to collect qualitative data in this study. In-depth-interviews provide richer materials or pieces of information to the intended studies (Kothari, 2004). In-depth interview in this study was made with 15 individuals who are believed to provide rich and depth information about their life experiences and have closest information and knowledge about the sources of noise pollution and its effects. Semi-Structured interview questions were prepared to deal with the informants. The informants were selected in purposive sampling from government offices, from the areas which are most vulnerable to a high level of noise pollution and individuals who have personal experience on the effect of noise pollution.

Key informant interview was made with selected 5 key informants from the city that has closest knowledge and information in the subject matter. The researcher dealt with key informants from the Environmental protection Office, Town Attorney Office, from the Office of Peace and Security, the city's municipality, and Mayor Office with unstructured interview questions. One FGD which hold eight individuals was made in the study which included representatives from all four kebeles. Observation method is employed in the study to see the information's in the investigators own way without asking the respondent to eliminate subjective bias, to obtain information on current happenings and to minimize the effect of past practice (Kothari, 2004). The researcher observed different settings of the city. Congested roads, religious organizations, recreational centres, schools and health centres and related settings were observed by the help of observation check list.

\subsection{Sources of Data}

Both primary and secondary data were used in this research work. To gather the primary data, variety of the qualitative and quantitative data collection instruments were employed; such as key informant interview, in-depth interview, Focus Group Discussion (FGDs), observation and questionnaire were employed. To indorse data from interview, FGD, Questionnaires and observation; a thorough document analysis was done to secondary data on 
ISSN 2250-3153

policies, laws and regulations. Internets sources, documents from zone and city offices were duly collected. Reports of the offices, applications from residents, laws and policies are reviewed in the study.

\subsection{Sampling Procedures and Sample size}

By using Yamane (1967: 889) formula the researcher selected samples. 93\% confidence level and $\mathrm{p}=0.07$ was employed in the selection of samples. There are 15,000 households that live in four kebeles which are selected purposively to this study; that are; Wadu Amba, Fana Womba, Markato Yushuwaa and Mehal Kebeles.

$$
\text { Therefore; } n=\frac{N}{1-N(e) 2}
$$

Where; $\mathrm{n}$ is sample size, $\mathrm{N}$ is population and $e$ are the level of precision

$$
\mathrm{N}=15,000 \text { households, } \mathrm{e}=0.07 \quad n=\frac{15,000}{1-15,000(0.07) 2}=201
$$

A total of 201 households were selected to respond to the questionnaire through systematic random sampling procedures. Also, 15 individuals for in depth-interview and five (05) individuals for key informant interview were selected. Eight (08) individuals were selected to focus group discussion (FGD) to discuss in group who represent four kebeles. In a total of 229 samples selected through random sampling by employing both probability and nonprobability samplings.

\subsection{Sampling Procedures}

Since the study relies on both quantitative and qualitative approaches, both probability and non-probability sampling procedures were employed in the study.

\subsubsection{Probability Sampling}

The probability sampling procedure used in this research is systematic random sampling. The collected lists of households from the record of kebele office and determined the sample per kebele based on the size of the population in each kebele using sampling proportional to the size of the population. Accordingly, 50 (25\%) from Markato Yushuwa kebele, 49 (24\%) from Wadu Amba kebele, 50(25\%) from Fana Womba kebele and 52 (26\%) from Mehal kebele, totally 201 households were included in this study. Then the unit of analysis (households) was selected from the given lists of households in each kebele systematically.

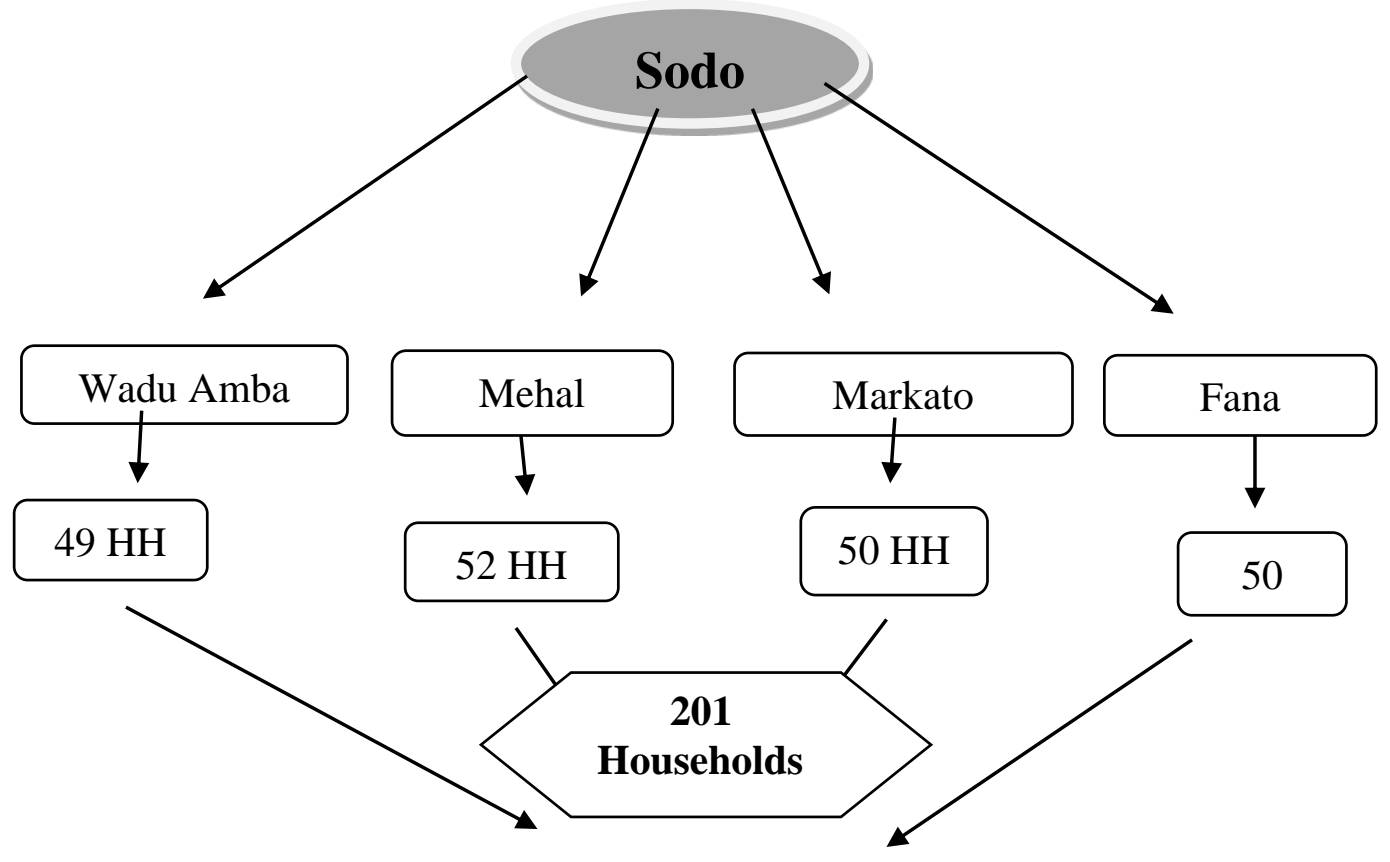

Figure 02: - Diagram of survey samples 
ISSN 2250-3153

\subsubsection{Non-Probability Sampling}

Among the non-probability sampling techniques, the purposive sampling technique was employed in the study. In-depth interview informants, Key-informant interview informants and focus group discussion participants were selected by using purposive sampling procedure.

\subsection{Data Collection Instruments}

Both quantitative data collection instruments and qualitative data collection instruments were employed in the study. The quantitative data collection instrument in this study was questionnaire. A questionnaire was prepared to collect data from 201 respondents. Questions derived from the specific objectives of the study were prepared to collect quantitative data. To measure the attitude of the respondents Likert scale questions were included in the questionnaire. Qualitative data collection instruments in this study include key informant interview guide, in-depth interview guide, FGD guide and observation checklist. Semi-structured interview questions derived from the specific objectives were prepared and the researcher dealt with the informants who were purposely selected to in-depth interview, who are considered as giving matured information on the issue at hand. The unstructured interview guide was prepared to key informant interview to get matured information. Individuals from different offices; from Sodo city Mayor office, from Municipality, from Sodo city Environmental office, from Sodo city Attorney's office and from Sodo city Peace and Security office were interviewed as a key informant in the study. An observation checklist was prepared to observe different situations of noise pollution in the study area. In addition to the observation checklist, the sound measuring device was applied to compare the noise pollution level in the selected catchment areas of the study in the city at different times.

\subsection{Method of Data analysis}

Data was presented, interpreted and thoroughly analysed as per the rules of the quantitative and qualitative data analysis method. Qualitative and quantitative data were analysed separately so that they complement and supplement each other. Quantitative data were analysed by the quantitative way; results of the questionnaire were analysed by the use of SPSS, v.20. Qualitative data from observations, FGDs, and in-depth interviews are analysed through manual theme and content analysis.

\subsection{Ethics, Consent and Permission}

Research ethics require that the researcher must ensure the confidentiality of the research participants and protect them from any harm (Creswell, 2009). In line with this, the research was carried out according to the ethical guidelines of Wolaita Sodo University. Approval of this study was obtained from the College of Social Sciences and Humanities of Wolaita Sodo University. Before interviews and discussions, verbal informed consent was elicited from research participants to record their voices. Participants were thoroughly explained on their rights and the purpose of the research. Care was taken to ensure participants know their responses would be kept anonymous and confidential.

\section{RESULTS AND DISCUSSIONS}

\subsection{Noisy situations, noise levels, noisy times and noisy days}

Survey study was done to differentiate noisy situations, noise levels, noisy time and noisy days in the study area and the result is given in the following table.

\section{Table 1: - Survey results on noisy situations, noise level, noisy time and noisy days}

\section{Frequency Percent}

The Noisy situations in the study area

$\begin{array}{lll}\text { No } & 58 & 28.9 \\ \text { Yes } & 143 & 71.1 \\ \text { Total } & 201 & 100.0 \\ \text { level in study area } & & \\ \text { low } & 4 & 2.0 \\ & 29 & 14.4 \\ \text { m } & 16 & 8.0\end{array}$

This publication is licensed under Creative Commons Attribution CC BY. 
ISSN 2250-3153

High

very high

Total

Noisy times in the study area

Morning

Day time

Evening

Mid night

Whole day

Whole night

Total

Noisy days in the study area

Working days (Monday - Friday)

Weekends (Saturday \& Sunday

All days

Total

Source: own survey 2020
85

67

201

34

17

25

38

27

60

201

59

75

67

201
42.3

33.3

100.0

16.9

8.5

12.4

18.9

13.4

29.9

100.0

29.4

37.3

33.3

100.0

Table 1 shows survey results on noisy situations, noise level, noisy time and noisy days in the study area. From 201 total respondents, $143(71.1 \%)$ are facing noisy situations in their residential area, workplace or school area, while the remaining 58 (28.9\%) are not sure or are not facing a noisy situation in their environment. The majority of people living, working or studying in the study area are facing noisy situations in their daily life and their activities, while the rest are not facing a noisy situation or they do not consider it as a problem or they accepted it as a positive situation which indicates modernity, urbanization, industrialization, etc.

According to table 1 above, from 201 total respondents 67 (33.3\%) levelled the noise level in the study area as very high, $85(42.3 \%)$ levelled it as high, $16(8 \%)$ levelled it as a medium, $29(14.4 \%)$ levelled it as low and only 4 (2\%) respondents levelled it as very low. Concerning noisy days in the study area, from a total of 201 respondents, 67 (33.3\%) said all days of weeks are noisy in the study area, while $75(37.3 \%)$ levelled weekends are noisy and 59 $(29.4 \%)$ agreed in working days are noisier than other days in the study area.

As it is given in survey results in the above table (Table 1), the majority of people living, working and studying in the study area are facing noise pollution the whole night. It is because of the different activities performed at night. Night times lack different movements and activities which balance the noise level in the environment. There is no traffic congestion and limited vehicle movements, no or limited people conversations, no business activities and markets at night, no or little wood and metalwork, garage and welding activities are limited or closed at night time and people are going to rest, doors are closed, movements are limited and ecosystem become silent at night time. Because of these little noises released at night time disturb whole community and all living nature.

Some movements and activities release noises which disturb the environment in the study area at night time. People are relaxing at different recreational centres as night clubs, bars \& restaurants; while others praying and worshipping at religious centres or in a group within their neighbourhood and in different chapels at night time. Both recreational and religious happenings emanate noises at night time which pollutes the environment. There are a number of prayers and worships in different religious institutions in the evening and in the midnight, there are also many neighbourhood programs in the evening. The presence of the religious programs or worship by itself does not create a noisy situation, but the practice of using loudspeakers to prayers; small group programs at neighbourhood and using out speakers in religious centres at midnight are aggravating the problem of noise pollution in the study area. Noises from night clubs are making boring their night time to people vulnerable to the problem. An enormous number of residents in the study area are facing high disturbances from night clubs located adjacent to their residences.

Alike noisy time which differs from time to time, at day and night, noise also differs from one day to another day based on different activities performed in different days and nature of the days within the week. Globally days of the week are classified into working days and weekends, but activities in these days differ from community to community and differ between different religions. In working days, the community faces noises from work-related sources and in weekends people face noises mostly from recreational centres, religious institutions and social events. 
ISSN 2250-3153

Weekends are noisier than working days in the study area. Different factors contributed to this; one is most religious institutions have their regular and special programs at weekends, (Regular program is a weekly program or fixed programs, while the special program is programs like; conference, thanksgiving and other celebrities). The other is high numbers of social events which use loudspeakers as a wedding, thanksgiving, birthday, and other celebrities, announcements and activations, etc. are taking place at weekends.

\subsection{Sources of Noise Pollution}

Survey study was done to identify the respondent's agreement on major sources of urban noise pollution in the study area and the result is given in the following table.

\section{Table 2: Survey results on sources of noise pollution}

\section{$\mathbf{s} / \mathbf{n} \quad$ Statement}

1 Noises from loud speakers of religious institutions are disturbing my residential/work/ school area.

2 Noises from Traffic congestion and vehicles are affecting my residential/work/school area.

\section{Responses}

Strongly disagree

Disagree

Agree

Strongly agree

Total

Strongly disagree

Disagree

Agree

Strongly agree

Total

Strongly disagree

Noises from Recreational centres, (Bars, restaurants, Cafes, Groceries and night clubs) disturbing my residential/work/school area.

$$
\text { A }
$$

Agree

Strongly agree

Total

\section{Frequency}

2

5

90

104

201

4

5

92

100

201

7

10

82

102

Strongly disagree

Disagree

Agree

Strongly agree

Total

Strongly disagree

Disagree

Agree

Strongly agree

Total

Strongly disagree

Disagree

Agree

Strongly agree

Total

Strongly disagree

Disagree

Agree

\section{7}

Percent

1.0

2.5

44.8

51.7

100.0

2.0

2.5

45.8

49.8

100.0

3.5

5.0

40.8

50.7

100.0

13.5

14.4

23.9

48.2

100.0

39.3

40.8

9.5

10.4

100.0

38.3

100.0

37.8

41.3

8.5

This publication is licensed under Creative Commons Attribution CC BY. http://dx.doi.org/10.29322/IJSRP.11.07.2021.p11534 
ISSN 2250-3153

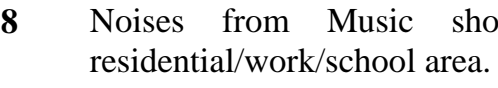

Strongly agree
Total

are are not disturbing my

Agree

Strongly agree

Agree
Strong
Total
Strong
Disagr
Agree
Strong
Total

Strongly disagree

Disagree

Agree
Strongly
Total
Strongly
Disagree
Agree
Strongly
Total

Strongly agree

Agree
Strong
Total
Strong
Disagr
Agree
Strong
Total

Source: - own survey

Findings of this study highlights that the streets and residential areas of wolaita Sodo city and some noisesensitive institutions in the city as schools, hospitals and etc in the study area are facing ear splitting noises from different noise sources. It is no longer awful to find big churches and mosques at the middle of residential areas, near to schools and hospitals; nor residential quarter housings are hosting nightclubs, bars, churches, congregations and mosques are getting piercing by day and night by using loudspeakers which yield higher noises which is far from tolerable level and it is very common to use horn speakers in all religious institutions in the city.

Based on the survey results given above and data gained from interview and FGD; the sources of noise pollution in the study area include; traffic congestion and vehicles as heavy and old vehicles, two-wheel motor cycles, Force Bajaj's, religious institutions loudspeakers, wood and metal work machines, announcements by loud speakers, night clubs, bars \& restaurants, building and construction works, Garage and welding activities and Music shops. The results from questionnaire given in the table above and findings on the sources of noise pollution are detailed and summarized in the following sections.

\subsubsection{Traffic congestion and different Vehicles as a source of noise pollution}

It is supposed that transportation noise is the main source of environmental noise pollution in urban centres, including road traffic, rail traffic and air traffic. As a general rule, larger and heavier vehicles emit more noises than smaller and lighter vehicles. While modern vehicles are designed to limit noise, some people make illegal modifications to exhaust systems, which are designed to create obnoxious noise (Bhatia, 2014; WHO, 2001).

The results of current study shows that majority of respondents agreed to traffic congestion and vehicles as source of noise pollution in the study area. As it is given in table 2 above from 201 total respondents 194 (96.5\%) respondents agreed to noises from traffic congestion and vehicles as a source of noise pollution in the study area and they are facing noisy situations from traffic congestion and vehicles in their residence, work place and school, and only $7(3.5 \%)$ respondents disagree to traffic congestion and different vehicles as source of noise pollution.

Related to its rapid urbanization process and an increasing number of vehicles in the city, there is high traffic congestion which is resulting in traffic noise pollution. Most vehicles; many public transport buses and cargo vehicles in the city are old and which are not repaired by their right seasons. Also, no serious follow up is made by the responsible governing bodies and nobody is looking at it as a serious problem, since they have a multi-faced effect on the environment and citizens.

The Force Bajajes (three-wheel taxi) used as public taxi transport in the city is emanating high noises to the environment. By their nature force bajajes are noisier, but the fact in sodo city is far from the reality of their nature. There are different extra factors for these vehicles to emanate high noises and disturb the residents. The rapid increase in the number of force bajajes for public transport in the city is one factor for the problem. When the population 
number increase in the cities, it is well known that the need for public transport will increase, which increase the demand and challenge the supply efforts of cities. It is important to facilitate additional public transport access by following public demand in the cities.

Big cities of Ethiopia and other countries are solving highly increasing public interest on city transportation by allowing public buses in their cities, but in Sodo city efforts to facilitate mass transportation access is very weak, while the population number is increasing in high speed and the demand for mass transportation is becoming very crucial. It is commonly observed that the number of Force bajaje is increasing from time to time.

According to Wolaita sodo city transport office report (2009) there were 1,259 bajaje vehicles in the city, which include Tagro Bajajes and Force Bajajes. Assuming half are force bajajes, there are around 630 (six hundred thirty) force bajajes in the city. This number doesn't include the number of force bajajes which are imported to the city after 2009 E.C. There are only two main roads where force bajajes gives transport services to public; Ajip to Otona route and Ajip to University routes; if we make random distribution to each route; in each route there are three hundred (300) force bajajes, but the force bajajes which work from University to Ajip are greater in number than other routes. So, it is clear that main roads in the city are crowded and there is high nuisance from these vehicles. Noises from Force bajaji is very high and people are unable to respond even to their cell phone call when they are travelling by force bajajes or walking and working around the main roads where they move, and many people are suffering from its noises and are getting afraid to travel by it or move around main roads where it move.

Some institutions like schools and health institutions near main roads are facing great challenge from noise pollution to operate their function properly. So, in addition to their noisy nature rapid increase in the number of force bajajes in the city is aggravating noise pollution from traffic congestion and vehicles. On the other hand, new force bajajes are emanating higher noises than old force bajajes. As it is seen in the observation with help of sound meter, the average noise from force bajajes which probably served up to one (1) year is $91 \mathrm{~dB}$ to $102 \mathrm{~dB}$ and force bajajes which served more than two (2) years is from $82 \mathrm{~dB}$ to $85 \mathrm{~dB}$. Surprisingly the level of noise from force bajajes is decreasing when they serve long, they are getting low noisier when they go older in opposite to other vehicles which become noisier when they get older. To describe the situation of force bajajes and related factors in Sodo city which

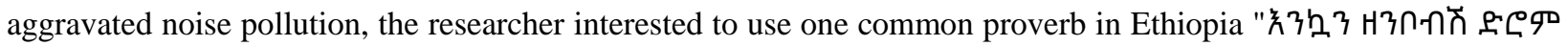
$\mathrm{mH}$ ל $\breve{n}$ !" meaning it is sufficient without adding additional factors. Rapid increase of force bajajes in Sodo city for public transport needs high attention in addition to other factors, for problem of noise pollution by the vehicle.

Some two-wheel motor bicycles are also releasing high noises and there is also have a high accountability problem by the users and drivers of the vehicle. It is well known that two-wheel motor bicycles are becoming potential sources of many problems not only in Sodo city also in many urban centres of Ethiopia, as a traffic accident, robbery, contraband, theft, crime, etc. But one undermined problem related to two-wheel motor vehicles is they are becoming potential sources of noise pollution in the cities. Illegal modifications, not repairing in right season, nature of some two-wheel vehicles and other related factors are contributing highly to the problem.

One of the greatest issues with this problem is the behaviour of drivers of two-wheel motor vehicles. The driver's behaviour of all vehicles is the greatest factor in transportation noise pollution, but the problem of two-wheel motor vehicle drivers, especially those who use the vehicle for renting purposes is very crucial in emanating noise pollution in the study area. They are disturbing the city by making beep-beep-beep in group which make a noisy situation.

Drivers are making traffic congestion and noise from the vehicles they drive. The street from University to Ajip is commonly seen getting congested because of different factors; as the narrowness of the road, weak management in the road and behaviours of drivers are factors making the road busy and vulnerable to different problems. The narrowness of the road and weak management of the roads are indeed serious factors which need high attention not only to getting safe from traffic noise, but to minimize traffic accidents and to minimize the vulnerability to different other related problems. In the case of driver's behaviour, it is commonly observed that drivers are creating traffic congestion in the road from University to Ajip. These can be articulated in picking and dropping materials, objects and people in narrow road, turning back within narrow road, parking in narrow road and etc. When they do these the road is closed to other vehicles and the car alarm which is very disturbing start by other drivers. The other behaviour of drivers is making car alarm (beep-beep-beep) the vehicle for long time and in high volume for simple remarks and greetings. Making alarm /beep-beep-beep/ in a group at residential area, school, hospital and other sensitive areas becoming more common in the city. The carelessness or un criticality of drivers in making alarm in high volume and picking and dropping objects and people without right place is becoming potential source of noise pollution in Sodo City.

Making illegal modifications to the vehicles is also the other factor which is supporting the problem of noise pollution in the study area. The attempt of making modifications to some vehicles by changing their service giving 
ISSN 2250-3153

status, especially using two-wheel vehicles to cargo by modifying is becoming very common in the study area, modifying $i s u z u$ car which gives cargo service to public transport is also very common.

In public transports and taxi in the study area it is very common to open music in loud speakers within and outside the vehicle by rejecting the will of passengers in the vehicle and outside community around the road. One of the informants said the following regarding the problem in the interview;

Box 1: Interview with vulnerable individual from Merkato Yushuwaa kebele;
“... Public transport buses, bajajes and two-wheel motor vehicles in the city are opening music in a high volume,
they don't care about passengers inside the vehicles and people living around the roads. Inside the vehicles
sometimes they are not willing to shut down even if they asked by passengers to respond their phone call. When the
vehicles which open music in high volume pass through the road the environment is shaking. Let I can share the
problem I face one day; "I am returning to Sodo from somewhere in public bus, the music opened in high volume
in the bus and it is impossible to talk with people sitting next to you; when the driver asked by the passengers to
minimize the volume of music, he was not volunteer to do that, when one went to inform; he was minimize to a
moment and can return to high volume immediately and etc... lastly when I arrive where I will exit the bus and
shouting to stop the bus; the driver has never listened my shouting and drives the bus up to bus station, I have highly
blamed him and we have highly conflicted..."

It is clear that traffic noise is inevitable; but cities can minimize traffic noises by maintaining roads, constructing sound barriers, reducing vehicle speeds, enforcing illegal vehicle modifications, carefully routing freight trucks, choosing electric buses and increasing the use of public transit, bicycles, walking and etc (Bhatia, 2014). Putting the sign of not making noise around some institutions and silent zones is the other way of preventing those institutions and areas from noise pollution. In Sodo city there is no sign of not making noise around sensitive institutions and silent areas. Even higher hospitals located in the study area found near big route road are lacked the sign of not making noise.

\subsubsection{Religious institutions loud speakers as a source of noise pollution}

The other finding in this study on sources of noise pollution is religious institutions loud speakers. Noises from religious institutions are not being addressed in Ethiopia, probably due to the fear of disrupting the long tradition between different denominations (Mintesnot, 2018).

The survey respondents were asked that if they agree or disagree with religious institutions loud speakers and out speakers /horn speakers/ are disturbing their residential areas, work places and school areas by producing noisy sound more than tolerable level and it is summarized in table 2 above. Majority respondents, from 201 total respondents $192(95.6 \%)$ responded they agree to religious institutions loud speakers as sources of noise pollution in the study area and the remaining only $9(4.5 \%)$ respondents disagree to religious institutions loud speakers as source of noise pollution in the study area. According to Wolaita zone peace and security department report (2019); there are 120 different types of legally registered religious institutions and denominations in Sodo city. There are a number of new religious organizations emerging in the city from time to time. As it is assured by interview with key informants, it is common in Sodo city to see religious institutions in each and every residential village of the city by renting 200 square meter place, sheltering it with shanty materials and undergoing programs by using loud speakers. People living close to these institutions are in continuous disturbance and exposed to the effects of noise pollution. Many religious institutions regularly open loudspeakers and start to pray at midnight. They use the Horn speakers by putting it at the higher place in their compound to have listened in long distance. This may disturb the sleep of the people living around those congregations. As it is observed in the interview and FGD most dwellers of the study area are facing problem from noises from religious institutions loud speakers.

As it is observed in the city, there are around three up to eight religious' institutions in each village of the study area. Many religious institutions in the city are constructed with shanty materials which cannot hold noises within their hall and are using loud speakers for their religious programs. 
According to Federal affairs minister proclamation no.01/2010, the standard to open religious institutions in one area is having 1,000 members for opening new religious institution and 500 members to open new ministry. But now the trend in the study area seems changed, some religious leaders need sound systems (loud speakers) more than followers or believers to open church /religious institutions or ministries. It is commonly observed that in Sodo city people are starting worships at any place by using loud speakers, even if they have no followers or very little followers. The distance between religious institutions is not the matter to open religious institutions. Proclamation 01/2010 also states the distance between two religious' institutions as $500 \mathrm{~m}$ in cities/towns and $600 \mathrm{~m}$ in rural areas, but in the study area it is observed that there are religious institutions opened in distance less than $300 \mathrm{~m}$, which is almost half the standard given by the government.

Misplacement of religious institutions with residential areas is very common in Sodo city. By principle religious institutions must not be placed in residential areas, even if it is the problem of many towns and cities in Ethiopia and is aggravated by different factors of urbanization, serious follow up and measures are needed. According to data gained from Peace and Security Office through KII \& document analysis, in Sodo city the problem of misplacement is very high. Any religious organization can open the other branch or the new one at any part in residential, business, near school and hospital and etc. People are using every residential house or business homes and others as church or mosque in any place in the city. Almost all residential, business, and other areas, even each \& every block and village contain at least one religious' denomination in the study area. Without any limitation any one can open church at any place in Sodo and can use loud speakers as he/she can have as much as possible. According to Key-interview informant from Sodo city Peace and Security Office, there are no practical regulations and rules which prevent anyone from opening religious institution in any place in the city and no one can limit them from using loud speakers with very high volume. The religious institutions opened in residential areas are mostly becoming potential sources of noise pollution in Sodo and the residents are suffering from it at day and night and these is becoming public discontent in the study area.

\subsubsection{Announcements by loud speakers as a source of noise pollution}

Noises from announcements in loud speakers are also the other aspect of findings in this study. The survey result given in table 2 above shows the majority respondents share the problem of noise pollution from announcements with loud speakers. From 201 sample respondents 183 (91.5\%) respondents agree to announcements by loud speakers are disturbing their residence, work place or school area and are source of noise pollution in the study area, and the remaining 18 (8.5\%) respondents disagree to announcements as source of noise pollution in the study area.

According to FDRE advertisement Proclamation 759/12, advertisements causing noise pollution through any sound magnifying machine are prohibited. On streets and residential areas of Sodo city it is very common to observe a car which carry a loud speaker and which announce and promotes some public, private or religious events which carry out some days after the announcements. The noise manipulated from this action is very disturbing. The most frequent announcement in the study area is religious announcement, that announces conferences and events organised in religious institutions.

Announcements in loud speakers without opt for sensitive regions, in residence, near hospitals, around schools $\&$ etc. are most common. Within seven weeks of frequent observation, which is from January 02/2020 to Feb 15/2020 more than 20 different denominations announcements were take place in Sodo city by using loud speakers. In the same time of period 5 announcements of football game takes place in the city. Other announcements as mobilization for tax payment, political announcements, private school mobilizations and others takes place in the city. In addition to using loud speakers for the announcement, the frequency they announce the same advertisement for many days and many times in the same day is also the major public discontent in the study area. They announce in each and every village by revolving many times.

\subsubsection{Night clubs as source of noise pollution}

The findings of this study also provide shreds of evidence that night clubs are sources of noise pollution in the study area. Table 2 above shows that from the total of 201 respondents $145(72.1 \%)$ respondents agreed with the disturbance of night clubs in their residential area by producing noise which is not tolerable, and the remaining 56 (27.9\%) disagree to night clubs as source of noise pollution in the study area.

People in the study area are suffering from noises from night clubs which are built and/or opened around residential areas. As the studies show the potential source of noise pollution in residential area are night clubs. There is music by loud speakers' whole night in Night clubs, people shout and over dance in night clubs. The loud speakers used by night clubs are very huge and prepared for the purpose of large stadiums or to big halls. One of respondents writes at back of the questionnaire paper the following statement; 
Night clubs are increasing highly in the city. Opening night clubs around residential areas and using loud speakers which make high noises in the neighbourhood, opening music in high volume by putting huge sound box outside the home is becoming accustomed practice in the study area.

\subsubsection{Music Shops as a source of noise pollution}

Noises from music shops are also other sources of noise pollution in the study area. The respondents were asked if they agree or disagree on the statement 'music shops are sources of noise pollution and they are facing noise pollution from music shops in their residence, workplace or school' and the result is summarized in table 2 above. Accordingly, from 201 sample respondents $161(80.1 \%)$ respondents agree to 'music shops are sources of noise pollution in the study area', and the remaining $40(19.9 \%)$ disagree to music shops as a source of noise pollution in the study area.

Music shops opened near schools and health centres are disturbing the operation of such institutions. Director of wolaita Sodo comprehensive preparatory \& high school shared the problem facing the school because of music shop opened around the school which is opening music in day and night with high volume that is disturbing the operation of the school. 


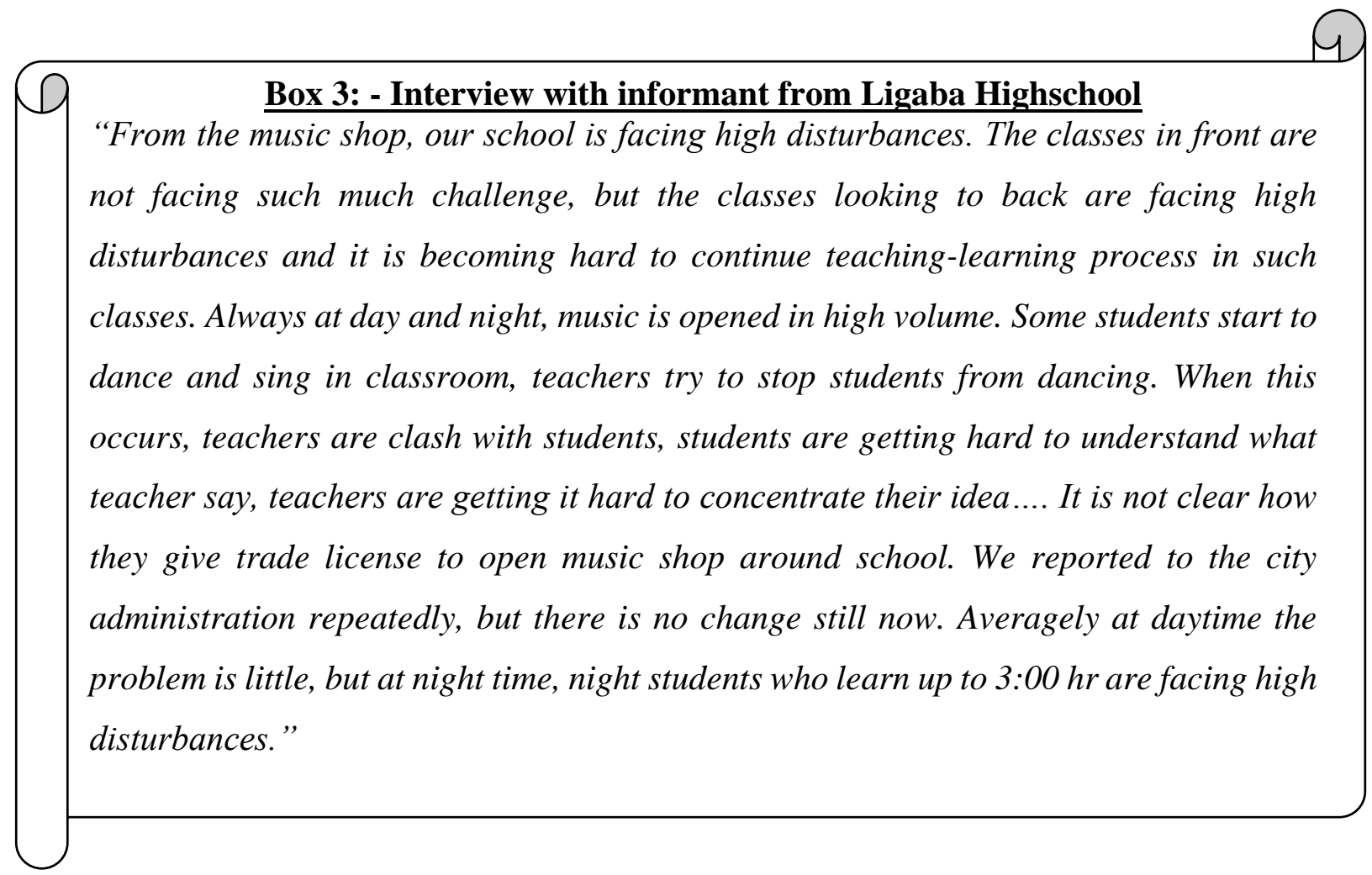

\subsubsection{Social Events as a source of Noise pollution}

Noise is at its peak in most of the social events. Whether it is marriage, parties, pub, disc or place of worship, people normally flout rules set by the local administration and create nuisance in the area. People play songs on full volume and dance till midnight which makes the condition of people living nearby pretty worse (Rinkesh, n.d).

Social events are the other features of urban areas which produce high noises that bring noise pollution in urban centres. Social events include weddings, funerals, and other cultural and spiritual celebrities are taking place in urban centres frequently and widely. There is a trend of singing, dancing, crying, and other collective activities which produce higher noises. Because of civilization and technological advancements, the trend of using sophisticated music equipment's is now becoming accustomed in urban areas. The possibility of accessing sophisticated music instruments in near locations with cheap costs or in a little rent is positively affecting the trend of using those instruments in social events. According to data gained from IIs, FGD \& observations weekends are busy with different events in the study area. Weddings, thanksgiving programs, birthday celebrations, graduations, holidays, cultural festivities, etc. which are getting high attention by the dwellers and using very loud music instruments is becoming very common. According to FGD report, when there is some ceremonial program in some individuals home in the neighbourhood, whole the neighbourhood face great trouble because of noise produced from music in addition to people's conversation. Household programs and ceremonies which contribute to noise pollution are increasing from time to time in the city. Data from observations and interview with the dwellers show that some people are opening geepas (high volume speaker) and television in a high volume at day and night for consecutive days after some ceremonies in their home, so the neighbours face noise problem.

Table 2 above shows that the majority respondents agree with social events as source of noise pollution in the study area. Accordingly, from total of 201 respondents, $145(72.6 \%)$ respondents agreed to social events are disturbing residence, work place and school and are source of noise pollution, $56(27.4 \%)$ respondents disagree to social events as source of noise pollution in the study area.

\subsubsection{Building and Construction Work as a source of noise pollution}

In urban centres, there is high rate of building and construction works. One building ends the other starts; these may cause noise pollution from machines it uses and conversation of workers in construction and building works. Under construction activities like mining, construction of bridges, dams, buildings, stations, roads, flyovers take place in almost every part of the world. These construction activities take place every day as we need more buildings, bridges to accommodate more people and to reduce traffic congestion. The down point is that this construction equipment is too noisy. It is known that buildings and construction work in urban centres are unending processes. When one building and construction ends the other starts and people are highly engaged in construction and building in urban centres. New buildings, renewing the part of or whole part of the buildings, building fences or renewing it is almost every day 
feature of urban centres. In construction work, it is very known that machines used for constructions, equipment, conversation of construction work are potential sources of noise (Rinknesh n.d).

With its rapid urbanization process, it is common to observe new buildings, constructions and renewal of old buildings from central part of the city to suburbs in Sodo city. This situation leads people living in the city to face noise pollution from buildings and constructions. The result of survey in this study also strengthens this argument as it is given in table 2 above the majority respondents; from 201 total respondents $159(79.1 \%)$ respondents agree to building and construction works as source of noise pollution in the study area, while the remaining $42(20.9 \%)$ respondents disagree to building and construction works as source of noise pollution.

\subsubsection{Wood Works, Metal Works, Garage and Welding works as source of noise pollution}

Wood and metal work machines are becoming a source of noise pollution in Sodo city in differing to their multi-dimensional support to individual uses, household uses, economic uses and other numerous bits of help. It is well known that the equipment's we use in our home, in our offices and schools, housings we are living and classrooms we are using to office are built and furnished with the products of wood and metal works. But the machines used to produce are very noisy in their operation and needs a series careful tactic in operating them and must be located in area separate from residential areas and noise sensitive institutions and organizations, but the situations in Sodo is different and are located and operating in irresponsible ways. Almost all wood and metal work machines are located in residential areas, near schools, health care centres and etc. There are also a bulky number of wood and metalwork machines in the study areas. Based on observations during this study there are averagely 3 to 7 wood and metal work machines in each village in the study area.

According to table 2 above the majority of the questionnaire respondents agreed to wood and metalwork machines as a source of noise pollution in the study area. From 201 total sample respondents, 156 (77.6\%) respondents agree to wood and metal-works machines and Garage and Welding works are disturbing in their residence/workplace/around school areas, while the remaining 45 (22.3\%) respondents disagree to wood and metalwork machines and Garage and Welding activities are a source of noise pollution in the study area.

The presence of Garage and Welding work by itself is not a source of noise pollution for the public, it may be the source of noise pollution for individuals who are working or using its service. But it became a challenge for the public because of its location in a residential area, workplaces, around schools or near hospitals. In Sodo city it is very common to make personal residence as business centres, mostly using for wood and metal work, Welding and Garage works. The top danger here is using the residence for such purposes without departure living in that home. People are using part of their own living home to work Garage and Welding or they rent part of their home to this purpose, but they are facing problem from unending noise from it.

\subsection{Extent of noise pollution from the major sources}

Based on the observation which takes place with the help of sound level measurement instrument (SLM) noise pollution extent of four kebele is summarized in the following table;

\section{Table 3: - Summary of the Extent of noise from Major sources summary in Sodo city}

$\begin{array}{ll}\mathbf{S} / \mathbf{N} & \text { Source of noise pollution } \\ \mathbf{1} & \text { Religious institutions loud speakers } \\ \mathbf{2} & \text { Traffic congestion } \\ \mathbf{3} & \text { Night clubs } \\ \mathbf{4} & \text { Wood \& metal work machines } \\ \mathbf{5} & \text { Different vehicles } \\ \mathbf{6} & \text { Announcements } \\ \mathbf{7} & \text { Music shops } \\ \mathbf{8} & \text { People conversations } \\ \mathbf{9} & \text { Small and large Industries } \\ \mathbf{1 0} & \text { Building and construction works } \\ \mathbf{1 1} & \text { Domestic equipment's }\end{array}$

Noise level in d
$90.5-101.3$
$88.5-111$
$97.5-129$
$82.75-105.75$
$86.5-103.4$
$107-134.5$
$95.75-126$
$78-94.75$
$87.25-110.5$
$86.5-108$
$88.5-103.5$

\section{Sources: - own survey 2020}

According to World Health organization guidelines (1999 \& 2001), the noise level must not be exceeded 55 decibels (dB) in residential, 65 decibels $(\mathrm{dB})$ in commercial, 75 decibels $(\mathrm{dB})$ in industrial and 50 decibels $(\mathrm{dB})$ in silence zone respectively at day time and 45, 55, 65 and $45 \mathrm{~dB}$ respectively in night times. By 140 decibels, sound becomes painful to the human ear, but ill effects, including hearing loss, set in at much lower levels. Noise level above $70 \mathrm{~dB}$ may cause harm to human health and consistently associated with decreased helping behaviour and increased aggressiveness (Boucher, 2019 \& Gour 2013).

As it is shown in the table above (table 3), the extent of noises from each source in the study area exceeds the recommendations and to some extent, it doubles the given tolerable level. The minimum $\mathrm{dB}$ recorded in the study area during this study is $78 \mathrm{~dB}$ from 
people conversations and the maximum $\mathrm{dB}$ is $134.5 \mathrm{~dB}$ from announcements. Even if there is no clear demarcation for commercial, residential, industrial and other areas in the city, it is clear that the noise level in all areas and from all sources in the study area exceeds the given standard.

\subsection{Factors behind the proliferation of noise pollution}

These are factors that aggravated the problem of noise pollution in the study area and they are grounds where sources of noise pollution stand on. The factors of noise pollution may or may not yield noise by themselves, but they helped sources of noise pollution to produce high noises and allowed more people to be affected by the problem. Let us see one by one:

\subsubsection{Rapid Urbanization}

Literatures show that urban areas are generally noisier than rural areas, because larger numbers of people live in urban areas. Urban noise levels are a complex mixture of noises from transportation, factories, industries, machines and people (Farooq, 2016).

The level of City development is partly measured by its system of governance as well as the nature of urban services. Accordingly, the municipality of Sodo city was established in the year 1945. When we look to the development of urban service in Sodo city according to 2016 \& 2017 data, there were 52 schools, 1 university, 1 College of Agriculture, 1 TVET and 4 private colleges; there were 2 Hospitals, 3 health centres, 6 Health Posts, 9 Medium Clinics, 21 clinics, 5 Pharmacies, 21 Drug Stores, 7 Rural Drug stores, 2 Medicine Distributors and 1 Medical Laboratory (Wolaita Sodo city profile, 2018). The development of these service giving sectors has its own greater effect on the upswing of noise level and vulnerability to its effect.

The city has one general market which is found at the centre of Markatto yushuwaa kebele which is the biggest market in Wolaita Zone and the majority attendants visit this market mostly at Saturday and it contributes higher to the vulnerability of the city to noise pollutants and has greater effect to rise in noise level.

When we look the plan of the city, the first city plan of Sodo was prepared in 1967 by Italian technical office called Conserzio Italiano, the second plan was prepared by Ministry of housing \& urban development \& municipal department in Dergue Regime and in 2007. Considering the increasing population and demands of social, economic and physical infrastructures, the third structure strategic development plan prepared envisaging guiding over all development of the city for the coming 10 years. Now the fourth city plan designed and applied in the city, which structured the city in to seven (07) kebeles, 19 (nineteen) districts, 59 sub districts and 379 stations. There are 120 religious' institutions in the city (10 Orthodox, 2 Catholic, 50 Evangelical, 30 Kale Hiwot, 1 Mekaneyesus, 1 Adventist, and 25 others and 4 Muslim Moqsues \& etc) (Wolaita Sodo city profile, 2018).

Structuring and restructuring of the city is one of the greatest factors in the urbanization process which adds surrounding villages to city and extends facilities including housing places for newcomers. So, structuring and restructuring is contributing to noise pollution by increasing population number and other urban facilities which will produce noises.

When we look at hotel development in the city, before ten years there was only one standardized hotel in Sodo. Now there are more than five international standard hotels in Sodo city and there are a number of local quality hotels in the city (Wolaita Sodo city profile, 2018). The presence of standard hotels and recreations will play greatest role to urban noise pollution by attracting more people to the city and introducing other latest technologies to the area.

During the socio-economy study of the city in 2010 E.C, there were 1,439 Kebele residence houses, 307 Kebele trade houses, 50 Kebele offices, 957 Condominium and 20,765 resident house units in the City and there were 5,788 renters. There were also 25 Zonal \& 20 City government institutions, 9 private and government banks, 52 schools, 120 religious' institutions, and 44 institutions which includes NGOs, Teachers' Union, Red Cross, College, TVET, University, Conference Hall, Development Association, Museum, Radio Station, and Branches of Federal and Regional Institution (Wolaita Sodo city profile, 2018).

There are 12-grain mills in Merkato sub-city and 3 grain mills in Arada sub city, 33 Wood and Metal Works most of which are in Mehal sub city 5 blocket fabrics in Mehal and 5 lumbering sites in Markato are existed in the city within three sub cities of the city administrations at present. Thus, services are currently serving the residents of the city the surrounding cities and entrants to the city most of which are located at Markato. The existing data indicated that there are 3 flour factories, 1 flexible metal manufacturing workshop, garment, plastic, soup, leather, milk \& milk products and other wood work and metal industries (Wolaita Sodo city profile, 2018).

These all are the factors related to rapid urbanization in the study area and the probabilities where noise pollution will be made. They contribute to noise pollution by increasing population number, extending the probability to introduce new technologies, maximizing the demands to bring different facilities, roads, vehicles, different service centres and making the management of the city very difficult.

\subsubsection{Population growth}

As the population grows, there is an increasing exposure to noise pollution in urban settings. According to 1994 population \& housing census of Ethiopia, the total population of Wolaita Sodo was 36,287. In 2007, the FDRE Central Statistics Agency conducted the third Population \& housing census survey and by then the total population of Wolaita Sodo town reached to 76,780. In 2017 population size of the city was above 254,295 (Wolaita Sodo city profile, 2018). The rapid development of the city population over years is given in the following table; 
Table 9: - Population size of Sodo city by census years

\begin{tabular}{|lllll|}
\hline Year & Population size & \multicolumn{2}{c}{ Remark } \\
\cline { 2 - 4 } & Male & Female & Total & \\
\hline $\mathbf{1 9 9 4}$ & 18,863 & 17,424 & 36287 & CSA \\
\hline $\mathbf{2 0 0 7}$ & 40,495 & 36,285 & 76,780 & CSA \\
\hline $\mathbf{2 0 1 5}$ & 70,170 & 63,015 & 133,185 & SNNPRS BoFED \\
\hline $\mathbf{2 0 1 7}$ & 125,855 & 128,440 & 254,295 & Sodo city Municipality \\
\hline
\end{tabular}

Source: CSA 1994 \& 2007, SNNPRS Finance \& Economic Development Bureau 2015

The reality behind the rapid growth of population is a natural migration trend from rural areas to cities which are experiencing an exponential growth in people, activity, vehicle, traffic congestion and therefore, pollution in various forms. If we consider that by 2050 it is forecasted that $70 \%$ of the global population will live in urban areas, ensuring both a sustainable economic and social environment represents a huge challenge. The increase in population and frenetic activity of our cities is causing a proportional increase in the noise generated by vehicle traffic, followed by industrial, business and night-life activity (Generico, 2016). So, it is clear that rapid increase in population number in the study area affected the city to emanate noise pollution. Following the ethnic based conflicts in Ethiopia in past years many people moved to Sodo city following its peaceful existence. So, population in Sodo city is highly increased in last few years which result in crisis of urban services.

\subsubsection{Poor urban planning and management}

Poor urban planning that leaves industrial, commercial and residential areas meshed up altogether, which in turn makes the job of enforcing noise control an incredibly active one. It is known that when there are rapid urbanization and rapid population growth, it is very challenging to manage it in a planned manner. It is highly dependent on demand and supply rate and supplying capacity of the city. Rapid urbanization and population growth is not the problem of developing countries only; it is also the challenge of developed nations (Elaina et al, 2018).

Urban planning, which is one of Ethiopia's weaknesses, also contributes significantly to noise pollution. It is very common and not be surprised to see industrial buildings next to hotels, residential areas, and schools. Slums, results of poor urban planning, are bonus sources of noise pollution (Dana, 2017).

The findings of this study shows that in Sodo city following the rapid urbanization and population growth, the demand for different services is increasing from day to day. People use old and unrepaired vehicles for transport which emanates highest noises. People use their living home for church service because of less access to get land for church, using loud speakers to preach rapidly increasing population, and etc.

On the other hand, the capacity of the city to provide the needed services is under great question. The demand of people is high, the supply in the city is low, when many people need something which is not sufficient enough to all; it needs high skill of management. The greater problem in the study area is poor management. The development of the city is not matched with the capacity of the administrative body to manage it effectively.

As it is seen in the field observations, the city format is not well planned and effectively managed. All institutions, organizations, businesses, residential areas and other sectors are located mixed with each other which need serious arrangement, and are disturbing the operation of one another. Urban facilities are not managed well; for example; transport facilities and roads. High traffic congestion in some roads while others are free, lack of mass transport and dependence on small vehicle which have small capacity of holding population. No serious follow up to repair of old vehicles, building and construction weaknesses and etc. some roads in the city are waiting whole day seeking the vehicle which pass through it, the other roads in opposite are highly busy by serving every kind of vehicles, people and etc.

\subsubsection{Road network and Increase in the number of vehicles}

The road coverage of the city looks; $56 \mathrm{~km}$ Asphalt Road, $82 \mathrm{~km}$ Cobblestone Road, $18 \mathrm{~km}$ Gravel Road, $4 \mathrm{~km}$ Red-Ash Road, $123 \mathrm{~km}$ Earthen Road and other rural roads, most of the roads are narrow, less than standard which are exposed to different accidents including noise pollution (Wolaita Sodo city profile, 2018). The transportation in Wolaita Sodo city took place by Bajaje, Motor Bike, city bus, mini, medium and large buses. Market goods transport mainly freight (cargo) cars which includes; Lorry, Isuzu or FSR (Wolaita Sodo town profile, 2018). The size of Wolaita Sodo bus station is not adequate for easy traffic flow of the traffic volume this is $2400 \mathrm{~m} 2$ areas for more than 877 public transport vehicles enter and go out per day. Wolaita Sodo city, which is the centre of the region with 7 main gates $\&$ at this time with regard to transport facilities, the city has one bus station (Wolaita Sodo city profile, 2018).

The bus station is giving service with the domination of midi-buses and mini-buses and more than 20,000 peoples visit and cross the city daily. According to report of the office of transport in 2009 E.C, Wolaita Sodo city is the departure to about 40 different parts 
of the country. Within the city there are 950 mini and medium buses, 1450 private motor bices, 1250 freight (cargo) cars and 1259 Bajaj's currently serving the population of the city and the surrounding in transporting goods and services in the city. (Wolaita Sodo city transport unit 2009 E.C report).

Following its gigantic and quick service in small size and tricky roads for suburbs and surrounding rural community, the rapid increase of two-wheel motorcycles is also another factor. The number of this motor cycle has increased in high rate in past five years and still now it is increasing. The governmental office, private companies, individuals who want to use for their personal subjects and youths who want to rent it and trying to lead their life by the rent are still joining the market of motor bicycle to purchase it. The major issue here is the contribution of two-wheel motors in noise pollution of the city. They contribute to noise pollution by their wheel, engine and alarming clacks, beep-beep-beep.

\subsubsection{Technological Advancement}

Technological advancement as the introduction of high-volume musical instruments, availability of them in a cheap cost, the access of renting in little cost and etc are factors which aggravated noise pollution in the study area in addition to other related factors.

Box 4 : interview with Music instrument distributor
"Renting music instruments is becoming very wise business. People want music
instruments in each and every celebration. It is known that the occurrence of Mourning,
Birthdays, thanks giving, yearly programs, weddings and etc is highly increased not
only in urban centres, but it is becoming accustomed in rural areas also. Individuals
prepare program by needing any reason and want to rent music loud music
instruments..."

As the information from interview with music instrument distributor in the city shows; it is very easy to have a huge musical instrument by buying it with cheap costs or by renting it in very little cost. Thanks to technology which provides different options from very little to very huge, from with higher capacity to very lower capacity, from cheap to very expensive. People can access all types of musical instrument by near their surroundings. According to the informant, accessing high volume music materials in Sodo is very easy and cost wise. Everybody can access loud speakers by buying it by birr 3,000 ETB to 180,000 ETB. In an option one can rent very expensive and high-quality high volume loud speakers by very little cost rent, it ranges from 1500 ETB to 2000 ETB per day. Almost many people in the study area are using loud speakers which are latest versions by rent for their different programs;

Also, in an advancement of technology there are little equipment's which can play music in high volume at any place. Cell phones people are using daily are also play music, memory card which can hold high volume music is also other technological advancement. Following the introduction of memory card and USB flash people are accessing every kind of music, audio or video, local, national or international music's easily. The introduction of music Instruments which cannot need the availability of electric power, which play more than two days on one charge is also the other factor. The availability of generators for high power-seeking instruments also affected noise pollution positively.

\subsubsection{Competition of religious institutions}

Ethiopia is suffering from an increasingly aggressive use of loudspeakers by religious groups who compete with each other over influence in the public sphere. In fact, it is a recent arrival in a formerly quiet and peaceful Ethiopia, which is so disturbing and which has prompted call for a concerted and sustained campaign against loudspeakers misuse in Ethiopia. To reach out more potential members, many religious groups have begun a strategic marketing campaign using new technology available on the market (Strecker, 2007; Solid, 2013).

Competition of religious institutions which is triggered by war of loud speakers is becoming possible factor for noise pollution in the study area. Almost all religious institutions use loud speakers with regard to their size or number of populations.

Survey was done to differentiate the reasons of religious institutions for using loud speakers in their institutions and the following reasons were differentiated.

- To remind and motivate their follower about the program they have in days of weeks.

- To win others who are not their members by preaching with loudspeakers from where they are living.

- Lack of responsibility by religious leaders to take care for the surrounding dwellers.

- Lack of the government officials to take legal measure on those churches and mosques.

- Carelessness of the village dwellers to accuse the offenders who making noise pollution. 
Big religious institutions join the competition or war of loud speakers to secure their status while the small (the minority) religious institutions join the competition to get acceptance by the community and to win more members from the community.

Religious competition, in general, is classified into two; internal competition and external competition. Internal competition is the competition of religious institutions which have the same teachings. The internal competition by itself has many facets, but the major issues which cause competition are lack of good governance, leadership competition, resource competition and etc. According to Wolaita zone peace and security department report (2010 EC), internal competition between religious institutions that have the same teachings is rooted in lack of good governance in those institutions, corruption and attempt of corruption in those institutions. The competitions lead to separation and to build the siblings around the same environment and start war of loud speakers. In Sodo city this kind of competition is most accustomed one among protestant churches (Wolaita zone peace \& security dept, 2010).

These competitions are not strong as internal competition and not frequent as it. The competition is taking place with one with majority population and the other with minority population. The majorities struggle to secure their status while the minority struggle to have more people and to have better status among community.

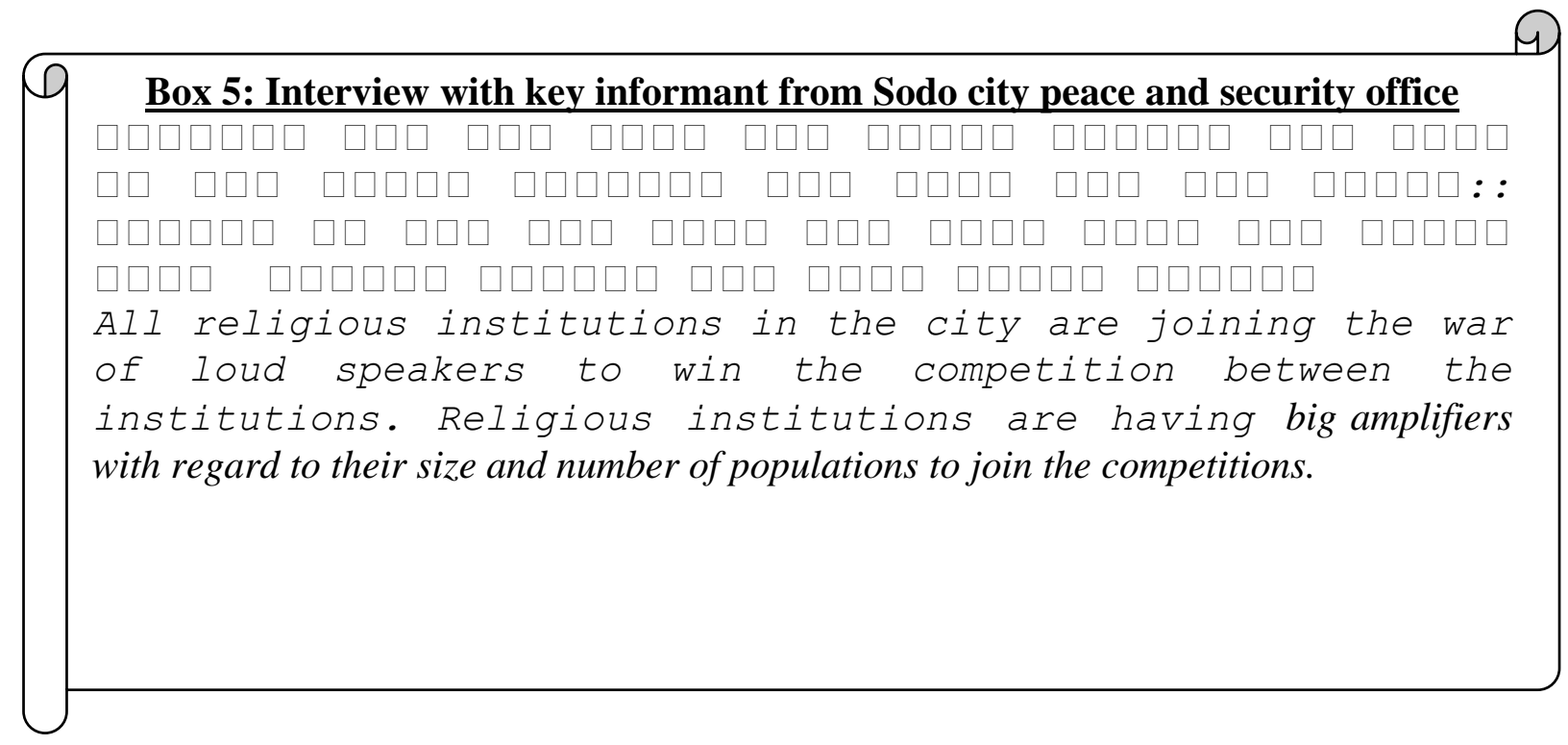

IV. CONCLUSION

In this investigation, the aim was to assess main sources of noise pollution, the extent each source emanates, and factors for the proliferation of urban noise. Religious institutions loud speakers, Traffic congestion, vehicles, Announcements by loud speakers, Night clubs and Recreational centres, Wood and metal work machines, Constructions and buildings, Garage and welding works are major sources of noise pollution. Factors for proliferation of the problem identified in the study are rapid urbanization, population growth, competition of religious institutions, road network, increased number of vehicles, technological advancement and poor urban planning and management.

The major gaps contributed to the proliferation of noise pollution in the study area are; lack of awareness in the community about sources and effects of noise pollution, misunderstand the way of exercising one's right, careless way of performing different activities, carelessness of community members for not struggling noise polluters, carelessness of governmental officials for taking measures on offenders, considering the problem as the problem of little individuals, lack of integration and cooperation among different stakeholders, lack of policy which specifically address the problem of noise pollution, etc.

In general, the problem of noise pollution in the study area is at a critical stage and needs the immediate intervention of community representatives, government, media, policymakers and other stakeholders.

\section{ACKNOWLEDGEMENT}

We would like to express gratitude to data collectors and supervisors who collected data and supervised the collectors. Also, we would like to appreciate the study participants for their willingness and participation in the study.

\section{Author's information}

MM: Masters of Art in Sociology, Lecture in department of Sociology, Madda Walabu University, Ethiopia.

TM: Assistant professor of Sociology, Lecture in Wolaita Sodo University.

\section{Authors' contribution}

MM: designed the study, wrote the proposal, handled data collection, analysed the data, drafted the paper and drafted the manuscript. 
TM: guided in the conception and design, approved the proposal, supervised analysis and approved final draft.

Conflict of Interest: The authors declare no conflict of interest.

\section{REFERENCES}

[1] Aberra Berhanu (2011); Environmental noise pollution in Addis Ababa, Major sources and Public reaction, Addis Ababa Environmental Protection Authority

[2] Adhan \& Iqamat (2010); Hizmetbook.org, loud speakers in mosques, CC BY-SA3.0, Wikipedia

[3] Babbie, E. (1994). Survey Research Methods. Wadsworth Publishing, Belmont, California

[4] Bhatia R , 2014; Noise Pollution: Managing the Challenge of Urban Sounds, Earth Journal Network, N/America, Latin America, Caribbean, East Asia, Europe, Middle, East \& North Africa, South Asia, Sub-Saharan Africa

[5] Blokhin A. (2019); Drawbacks of Industrialization, retrieved from https://www.investopedia.com/ask/answers/072815/what-are-some-drawbacksindustrialization.asp, on 20/02/2020

[6] Chappelow Jim, 2019; Industrialization, https://www.investopedia.com/terms/i/industrialization.asp

[7] CSA (1994 \& 2007), FDRE Central Statical Agency Census

[8] Creswell J. W, (2009); Research Design; Qualitative, Quantitative and Mixed Methods Approaches, Third edition, University of Nebraska-Lincoln, Los Angeles, London, New Delhi, Singapore

[9] Dana Doda (2017); An Assessment of Noise Pollution in Addis Ababa: The Case of Bole Michael Community Area, AAU, Ethiopia.

[10] Denzin N. K. \& Lincoln Y. S. (2008); Introduction: The discipline \& practice of qualitative research.

[11] Environmental Protection Authority (1997); Environmental Policy of Ethiopia, Addis Ababa

[12] Encyclopaedia Britannica (2013), science, noise pollution

[13] Essays, UK (2018); Technology has bad effects on environment, Essay in European Studies Retrieved from https://www.ukessays.com/essays/europeanstudies/technology-has-bad-effects-on-environment.php?vref=1 on 20/02/2020

[14] Elaine Carvalho da Paz, Thomas Jeferson Vieira and Paulo Henrique Trombetta Zannin; (2018); Urban Noise as an Environmental Impact Factor in the Urban Planning Process

[15] Farooq S; C\#01, 2016, Urban Noise pollution, department of Environmental \& conservation sciences, university of Swat, retrieved from https://www.slideshare.net/Saadfarooqi/urban-noise-pollution on 08/04/2020

[16] Federal Negarit Gazeta of the Federal Democratic Republic of Ethiopia, Dec.2002, AA, Ethiopia

[17] Gangwar, B.D. Joshi and A. Swami, (2006); Noise pollution at four selected Intersection in commercial areas of Bareilly Metro politan city, UP, Him J Enor and zool, 20(1).

[18] Ganguly Poushali, 2018; Effects of Industrial noise pollution, retrieved from https://helpsavenature.com/effects-of-industrial-noise-pollution on 20/03/2020

[19] Green William H, (2003); Econometric Analysis, 5th edition Pearson Education Inc, Upper Saddle River, New Jersey, 07458, New York University.

[20] Green WH (2008); Econometric Analysis, 6th Edition, Pearson Prentice Hall, Upper Saddle.

[21] Goines, L Hagler, L. (2007); Noise pollution, the modern plague, southern medical journal.

[22] Gonzalez A. E. (2014); What Does Noise pollution mean? Journal of Environmental Protection, Universidad de la República, Montevideo, Uruguay

[23] Harris, C.M. (1979); Handbook of Noise Control, New York: McGraw Hill.

[24] Hasset Assefa (2014); Noise pollution, Misuse of loudspeaker in Ethiopia, arresting sound pollution in Addis Ababa, Ethiopia.

[25] Kalkidan Yibeltal, (2009); Forum for Environment (FfE), Noisy Addis Ababa, Ethiopia.

[26] Kinfe Mesfin*, Abdrie Seid Hasen and Mohamed Birhanu, (2018); Determination of Noise Pollution Level in Dire-Dawa City, Research Article Volume 8, Issue 2, Ethiopia.

[27] Kothari C.R, (2004); Methods and Techniques, second edition, new age international publishers, Jaipur, India

[28] Lai, Patrick. (1996). Noise Pollution. In Major Environmental Issues Facing the 21st Century,

[29] Linde Sharon, n.d; what is Urbanization? - Definition \& Examples https://study.com/academy/lesson/what-is-urbanization-definition-examples.html

[30] Mahmoud F. El-Sharkawy, Ali S. R. Alsubaie, (n.d); Study of Environmental Noise Pollution in the University of Dammam Campus, Kingdom of Saudi Arabia.

[31] Mattia Grampella, Gianmaria Martini, Davide Scotti, Giovanni Zambon (2016); The factors affecting pollution and noise environmental costs of the current aircraft fleet: An econometric analysis, Transportation Research Part A, University of Milano, 20126 Milano, Ital

[32] Marianna Jacyna, Mariusz Wasiak, Konrad Lewczuk, Grzegorz Karoń; (2017); Noise and environmental pollution from transport: decisive problems in developing ecologically efficient transport systems; Warsaw, Poland.

[33] Mc Graw-Hill, (1997); Occupational and community noise, WHO; OMS: 390-418.

[34] Mintesnot G. Woldeamanuel, (2018); Noise pollution: an ignored problem of Addis Ababa, US Fulbright Scholar at Addis Ababa University and a Professor at California State University, Northridge.

[35] Mrinal Gour, (2013); Environmental studies, Osmania, University Hyderabad, India.

[36] Nicolas Pignier, (2015); The Impact of traffic Noise on Economy and Environment; a short literature study, Stockholm, Sweden.

[37] Randhawa S, (2017); Poor Urban planning increasing noise level, retrieved from https://www.pakistantoday.com.pk/2017/08/17/poor-urban-planning-increasingnoise-level-in-lhr/ on 04/03/2020

[38] Rediff.com news, (2000); No community has right to use microphones for prayer: SC, retrieved from (http://www.rediff.com/news/2000/aug/30loud.htm) on $03 / 05 / 2020$

[39] Sandhyarani N., (2018); 7 Corrective Solutions That'll Help Combat Noise Pollution Retrieved from https://helpsavenature.com/noise-pollution-solutions on $04 / 03 / 20$

[40] Singal S.P. (2005); Noise Pollution and Control Strategy, Alpha Science International Ltd: UK.

[41] SNNPRS, (2015); Finance \& Economic Development Bureau report, Awassa, southern Ethiopia

[42] Sollid S. H, (2013); Ethiopian churches in conflict, an empirical study of how the growth of a religious minority group can enforce a change in a religious majority group, University of Oslo. 
[43] Stake, R.E. (2010); Qualitative research: Studying how things work, New York: Guilford.

[44] Steve Morgan, (2015); Noise and Urbanization, Thought and Leadership, the science of silence, USA and Canada.

[45] The constitution of the federal democratic republic of Ethiopia, No.1, August, (1995), AA

[46] The Gardian Newspaper (2015); Indonesia bids to muffle noisy mosques, UK

[47] The Jerusalem Post (2016); Ministers approve bill muffing Muezzin's call to prayer

[48] Tsunokawa, Koji; Hoban, Christopher, Tsunokawa Koji* Hoban, Christopher, (1997); Roads and the environment: a handbook (English), World Bank technical paper; no. WTP 376. Washington, D.C: The World Bank, retrieved from http://documents.worldbank.org/curated/en/904041468766175280/Roads-and-theenvironment-a-handbook

[49] WHO (2018); Housing and Health Guidelines

[50] WHO (2001); Environmental Health criteria of noise pollution; Fact sheet, no 258, Geneva

[51] WHO (1999); Guidelines for community noise

[52] WHO (1997); Occupational and community noise, WHO, OMS: 390-418, Mc Graw-Hill

[53] UN, (2017); World Population Prospects, ttps://web.archive.org/web/20190626225001/https://esa.un.org/unpd/wpp/Publications/Files/WPP2017_KeyFindings.pdf

[54] Zenith Kucha, (2014); Evaluation of noise pollution in educational Institutions, Addis Ababa https://www.thereporterethiopia.com/article/noise-pollution-ignoredproblem-addis-ababa 29 September 2018, retrieved on 10/12/2019 https://www.lexico.com/en/definition/irritation, retrieved on 16/02/2020

[55] www.merriam-webster.com; "Definition of NOISE" Retrieved on 21/02/2020

\section{AUTHORS}

First Author - Melese Mesene, Department Of Sociology, College Of Social Sciences \& Humanities, Madda Walabu University, Bale Robe, Ethiopia, P.O Box 247

Second Author - Tamirat Mengistu, Department Of Sociology, College Of Social Science, Wolaita Sodo University, Wolaita Sodo, Ethiopia, P. O. Box: - 138

Correspondence Author - melesemsn@gmail.com, Tel:- +251-922311068 